\title{
Vibration characteristic responses due to transient mass loading on wind turbine blades
}

\author{
Mohammed Al-Hadad, Kristoffer K McKee, lan Howard \\ Mechanical Engineering, Curtin University, Australia, WA \\ m.alhadad@postgrad.curtin.edu.au
}

\begin{abstract}
Wind turbine blades can experience mass collision events during operations, either due to bird strikes or with other flying objects. The rapid impact loadings due to these events can cause fatigue damage leading to subsequent blade loss or even wind turbine system failure. This paper addresses the effects of transient loadings resulting from a rapid mass reduction event from the rotating blade as well as an impacting mass onto the wind turbine blade, leading to transient vibration and unbalance within the turbine system. The novelty of the research is that it shows the coupling between the blade in-plane with tower transverse (Zdirection) vibrations, and blade out-of-plane with tower front (Y-direction) vibrations which have been identified through different experiments. Measurements from an experimental small-scale horizontal axis wind turbine test rig are reported, instrumented with contact and non-contact sensors and rotating and non-rotating sensors, to investigate the various transient impact loading events. Additionally, the drive shaft vibration for different conditions has been monitored by utilizing orthogonal laser measurement for detecting the main shaft displacements towards perpendicular axes. Subsequent orbit analysis is presented showing the analysis of different shaft orders during the rapid mass reduction and mass collision events. Complex orbit and filtering analysis of shaft orders during the transient mass impact loading events are used to demonstrate the sensitivity of the sensors for further fault detection.
\end{abstract}

Keywords: wind turbine, vibration coupling, transient mass impact loading, coupled vibration, rotating sensors

\section{Introduction}

Laboratory scale investigation of various wind turbine fault case studies can assist in developing a comprehensive understanding of the transient vibrations that arise during these severe events. Transient fault diagnosis through fault modeling and monitoring the vibration response is a powerful technique for reducing further blade failures which occur after mass collision incidents. The transient collision of flying birds (e.g. bats and ducks) on the wind turbine blades can have a pronounced effect on reducing blade fatigue life. $\mathrm{Hu}$, et.al [1] modelled bird and bat collisions by launching small balls filled by water (eg, tennis balls) which did not cause damage to the rotating blades in the spanwise direction. The tests were 
implemented on an onshore 1.5 $\mathrm{MW}$ wind turbine in working condition, on which the balls were launched from the ground by a compressed air launcher to strike a certain point on the rotating blade. Data was accumulated from 6 accelerometers and high-quality microphones positioned in three blades by a developed data acquisition located in the nacelle. Additionally, for collision condition recording, a camera was placed at the bottom end of the nacelle for monitoring the launched ball trajectories.

Flowers, et al.[2] utilised the same tennis ball technique on a 6MW offshore wind turbine for monitoring bird collision on the rotating blades. Highly sensitive and integrated sensors were utilized such as; wireless accelerometers and cameras positioned in the blades and nacelle, a high-resolution camera located in the tower base connected directly by a cable with data acquisition, and high-quality microphones. Furthermore, the data acquisition system was located at $\mathbf{8 0}$ meters from the tower base. Utilizing the technique of launching water-filled tennis balls from 10 meters upwind was further involved to achieve potentially damaging collision with the rotating blades. This approach has the ability to detect the vibration sensor triggering limits when actual birds collide with the wind turbine blades.

Additionally, assessment of repetitive mass collision on wind turbine blades through vibration signal analysis and recorded images, helps to identify maintenance requirements and diminish further damages. Furthermore, blades that experience a collision from masses carried by storms and typhoons often obtain different size defects in the blade trailing edge and spanwise and sometimes lose segments from the blade structure due to impact with solid masses. These spots are deemed likely to cause crack initiation which can have further propagation stimulated by blade vibrations. Additionally, blade failure or high bending amplitude before the failure often leads to tower failure and wind turbine collapse $[3,4]$.

Chou et.al, [5] proved that wind turbine blades can withstand a maximum gust of $53 \mathrm{~m} / \mathrm{s}$ without any particular damage. Serious damage started with longitudinal cracks at the trailing edge resulting from decreases in the long-term toughness due to the instantaneous forces generated after that speed (e.g. from $80 \mathrm{~m} / \mathrm{s}$ wind speed). Further, Chen and Lin [6, 7] concluded that there are degradations in the wind turbine blade material properties when the rotor speed reaches $80 \mathrm{~m} / \mathrm{s}$ during an upwind gust, followed by a collapse in blade material properties which occurred during the higher $90 \mathrm{~m} / \mathrm{s}$ wind speed.

Fluctuations in wind speed and direction can also have a negative effect on the drive shaft. Fractures have been found in the wind turbine shaft after the bearing housing and before the gearbox due to high stresses which resulted from fluctuations of the blade rotational speed [8]. The transverse cracks around the drive shaft surfaces which have been identified during vibration condition monitoring, have been attributed to imbalance forces from the nonuniform wind speed during storms and hurricanes. The repetitive transient vibrations due to blades crossing the critical speeds converge to resonance frequencies, which assist in crack propagation [9, 10]. Additionally, exciting high-frequencies due to a collision of high-speed mass with the rotor blade can cause shaft vibration and increase the contact pressure between the gears. This has a negative effect on both the planetary gears and the inner surfaces of the rolling element bearings. Increasing blade out-of-plane vibration leads to shaft 
axial vibration increases and high impact in the contact points; and fatigue cracks nearby the fatigue source $[11,12]$.

This paper presents an analysis of transient mass loss and collision events from rotor blade case studies conducted with a small-scale horizontal axis wind turbine. The experiments involved artificial faults and subsequent monitoring of blade vibration condition at different modes (axial, in-plane, and out-of-plane), including results from tower response, and 2dimensional rotor shaft dynamic bending at orthogonal axes 1 and 2 and their effects at various rotor speeds.

\section{Test rig instrumentation}

To diagnose wind turbine operation faults, various sensor and monitoring options can be considered. This research demonstrates the use of rotating and non-rotating sensor measurements from a small horizontal axis wind turbine test rig that has been manufactured. The current test rig shown in figure 1 consists of three $1 \mathrm{~m}$ untwisted aluminum rotating blades connected to the hub by three short rods. An ABB servo motor is coupled to the hub via a hollow drive shaft with $25 \mathrm{~mm}$ and $9 \mathrm{~mm}$ outer and inner diameters respectively, supported by two bearings bolted to the upper base, itself positioned on a hollow tower of height $1.75 \mathrm{~m}$.

The ABB BSM90C-2150 motor has a continuous rating of $5 \mathrm{Nm}$ torque with a peak output of $15 \mathrm{Nm}$ and is used to drive the test rig using the accompanying MINT software. This provides the means by which vibration monitoring and fault diagnosis techniques can be explored through various case studies. Vibration condition monitoring on the test rig comprises of different sorts of sensors; rotating and non-rotating, contact and non-contact. Four groups of strain gauges represent the first rotating measurement sensors, three sets instrumented near the root of blade 1, to measure axial, in-plane, and out-of-plane dynamic strain, and one set positioned on blade 2 in the in-plane direction. A miniature piezoelectric accelerometer $(0.2$ g) has also been used to measure the rotating acceleration of blade 1 , positioned at the tip of the blade in the in-plane direction.

A low noise slip-ring assembly with 20 channels, Michigan Scientific SR20M, has been installed in the hub centre, connecting all the rotating sensor wires to the off-rig data acquisition system. A Michigan Scientific PS-AC strain gauge power supply was used to provide power to the strain gauges through the slip ring assembly. In addition, strain gauge amplifiers were mounted on the rotating hub, Michigan Scientific AMP-SG-MH-10, to amplify the strain gauge signals prior to the slip ring to provide the low noise dynamic strain measurement. The miniature Endevco Isotron 25A piezo accelerometer was also connected to the data acquisition system through the slip ring.

The non-rotating measurements include contact and non-contact sensors. The contact type consisted of a triaxial accelerometer, Bruel \& Kjaer 4506-B, mounted at the top of the tower, whereas the non-contact sensors comprised of laser measurement probes, GMBH MEL M5, located on the motor and shaft base plate for measuring the relative deflection of the main 
drive shaft. The laser probes were mounted orthogonally to the shaft in axes 1 and 2 , having $90^{\circ}$ between each probe, having a measurement range of $+/-1 \mathrm{~mm}$ [13]

The data acquisition system for the experiments utilised a National Instruments CompactDAQ system consisting of a NI-cDAQ-9178 chassis with several NI-9234 anti-aliasing analog signal modules. In addition, the digital encoder waveforms from the servo motor were captured by a NI-9361 8 channel digital input module. In-house MATLAB software was used for the data acquisition of the 18 channels of measurement data collected during the tests.
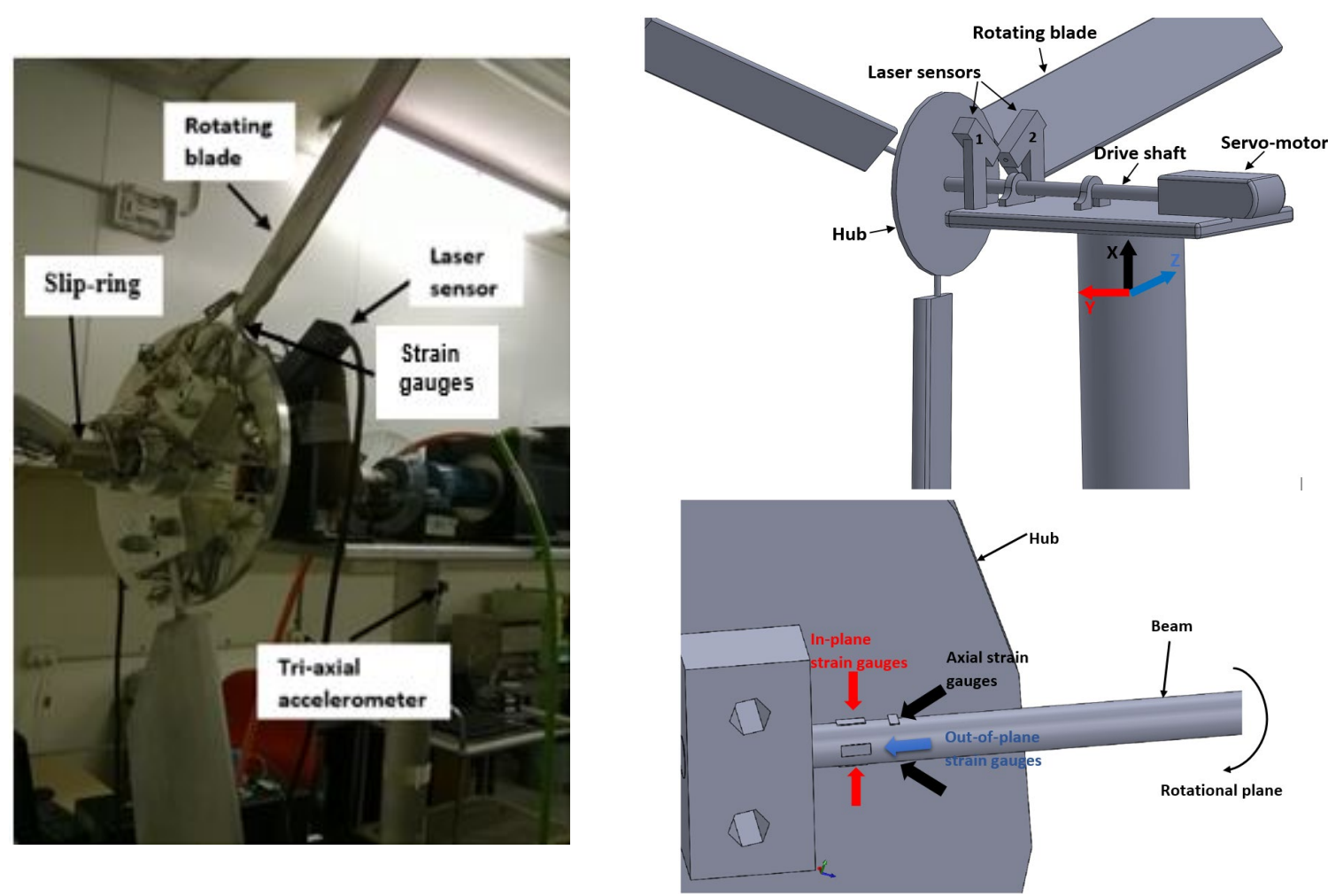

Figure 1. Small horizontal axis wind turbine test rig.

An emergency push-button was instrumented with the operating system to facilitate stopping the test to meet the safety requirements. Additionally, the test rig was installed in an isolated zone in a laboratory suitable for these tests. The researchers vacated the test zone and stood behind a barrier until the test was completed.

Table 1 shows the listing of the 18 channels of data acquisition utilized during the experiments. The dynamic sensor measurements were acquired simultaneously across all channels during the tests, sampled at $12.8 \mathrm{kHz}$, providing a means to achieve comprehensive monitoring of the test rig during the application of the various artificial faults. 
Table 1. Sensors used for dynamic measurements in the small-scale wind turbine test rig.

\begin{tabular}{|c|c|c|}
\hline Sensor Number & Sensor Type & Measurement \\
\hline 1 & Strain & Blade 1 - axial direction \\
\hline 2 & Strain & Blade 1 - in-plane direction \\
\hline 3 & Strain & Blade 1 - out-of-plane direction \\
\hline 4 & Strain & Blade 2 - in-plane direction \\
\hline $5-12$ & Digital Encoder & $\begin{array}{l}5-2500 \text { pulse per revolution } \\
6-1 \text { pulse per revolution } \\
7-2500 \text { pulse per revolution }\end{array}$ \\
\hline 13 & Piezoelectric accelerometer & On the tip of blade 1 \\
\hline $14-15$ & Laser measurement sensors & Orthogonal shaft displacement after bearing 2 \\
\hline $\begin{array}{l}16 \\
17 \\
18\end{array}$ & Triaxial accelerometer & $\begin{array}{l}\text { On top of the tower } \\
\mathrm{X} \text { - direction } \\
\mathrm{Y} \text { - direction } \\
\text { Z-direction }\end{array}$ \\
\hline
\end{tabular}

\section{Testing procedure}

Various experimental case studies were implemented for modelling the collision of objects onto the rotor blade. Figure 2 shows a typical shaft speed profile during a 60 second test, obtained by analysis of the once per revolution encoder signal. The shaft speed ramp-up and ramp-down phases can be seen as well as the steady state running period of the test after an initial transient element while the motor controller brought the shaft speed to the nominated $100 \mathrm{rpm}$ for this test.

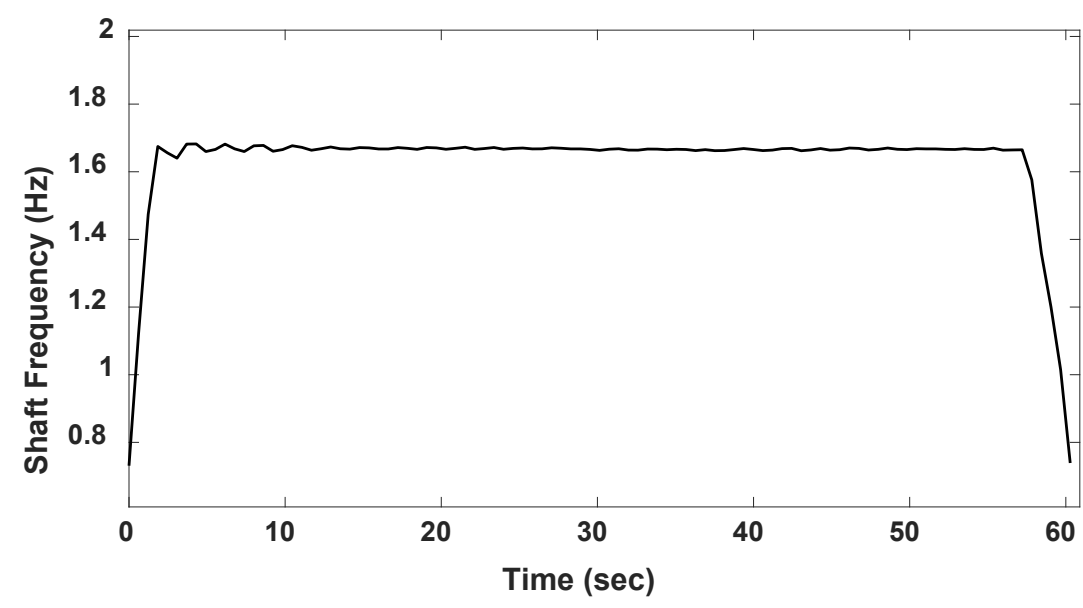

Figure 2. Rotor shaft speed profile during a typical test at $100 \mathrm{rpm}$.

\section{Transient mass removal from the rotor blade}

The loss of mass from the rotor blades is a serious issue during wind turbine operation. This has been simulated by experiments whereby a $200 \mathrm{~g}$ mass came off from the rotating blade at a speed of $100 \mathrm{rpm}$ during a 60 second test. In this test, a $200 \mathrm{~g}$ mass was added to the tip 
of blade 1, though it was not securely fastened. The rotor was then in an unbalanced state at the start of the test. At 49.65 seconds, while rotating at $100 \mathrm{rpm}$, the $200 \mathrm{~g}$ mass was lost from blade 1. After the mass reduction event, the rotor system then became balanced. This case study is known as the mass came-off or reduction event.

\subsection{Blade dynamic strain response}

Figure 3 shows the resulting dynamic strain measurements on blade 1 during the test when the mass came off. The low noise and clarity of the strain signals should be noted from the zoomed measurements on the right side of figure 3 , on all strain components. The initial unbalanced rotor situation can easily be seen on all three strain gauges for the first duration of the test, up to the mass reduction event. It can also be noted that the dynamic strain changes the most for the out-of-plane results when the mass reduction occurs, where the higher frequency components become more obvious. The instantaneous mass reduction is easily visible on all blade modes as in figure 3 , though it is more apparent on the axial and out-of-plane dynamic strain measurements.

(a)

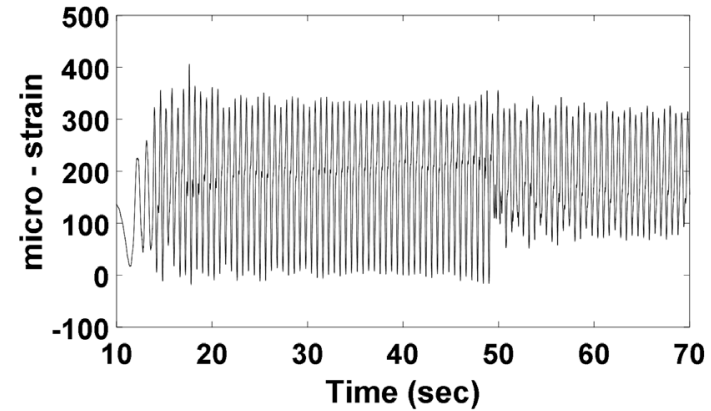

(b)

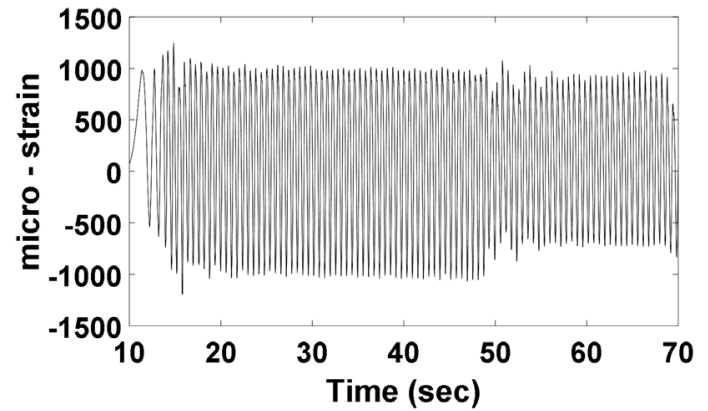

(c)

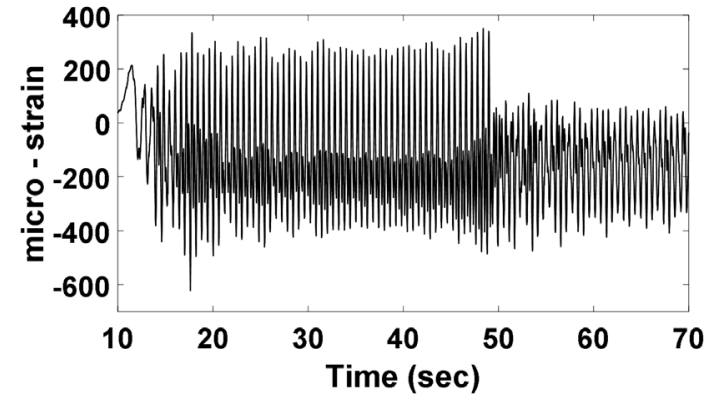

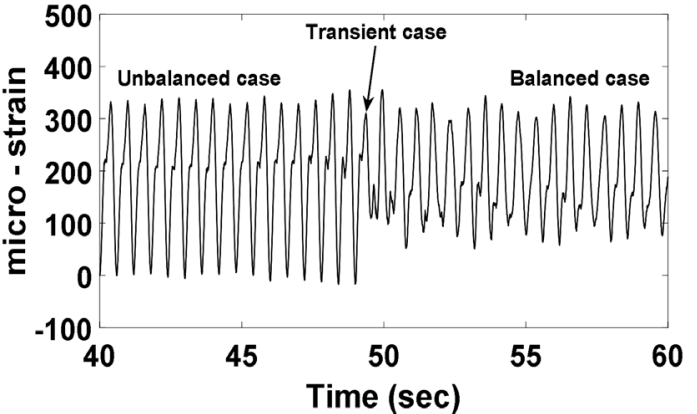
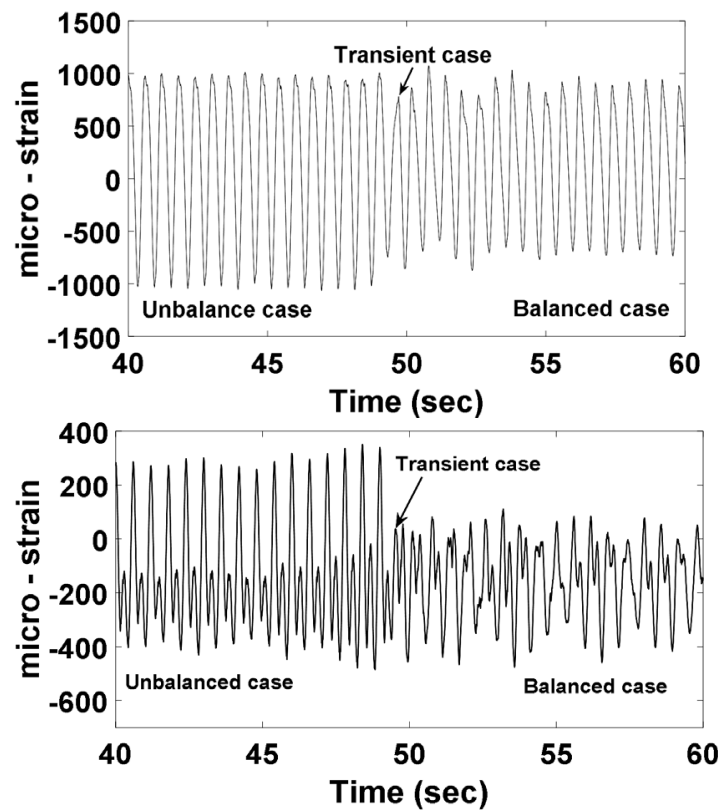

Figure 3. Transient 200 gram mass reduction event at $100 \mathrm{rpm}$ at $49.65 \mathrm{~s}$ a) axial, b) in-plane, and c) out-of-plane. 
The strain components were further analysed using synchronous signal averaging techniques, where the strain measurements at exact equi-spaced shaft phase measurements were averaged together, providing strain readings as a function of shaft rotation. These results are shown in figure 4 for three different test cases including the strain readings for the shaft rotation during the mass reduction event.

The axial and in-plane blade root strain results are predominantly once-per rotation oscillations, as seen in figures 3 and 4 . This is as expected from the gravity loading of the blades and the additional out of balance force from the added $200 \mathrm{~g}$ mass. The once-perrevolution behaviour is also observed in the out-of-plane blade root strain, though there is also a more obvious twice per rotation component.

It should be noted that the out-of-plane strain of the blade changes significantly with the unbalanced case and also when the mass removal occurs, in comparison to the balanced case as shown in figure 4c. This indicates that coupling occurs between the gravity loading and centrifugal forces on the blade and the out-of-plane dynamic motion of the blade. A small phase shift in the vibration response can be seen between the balanced and unbalanced cases in figure 4, for the out-of-plane and axial strain. The largest phase shift occurred for the outof-plane strain where the unbalanced situation resulted in a phase shift of 20 degrees at the maximum negative strain point. The blade angle of attack would be expected to influence this result and also the degree of coupling between the strain results.

a)

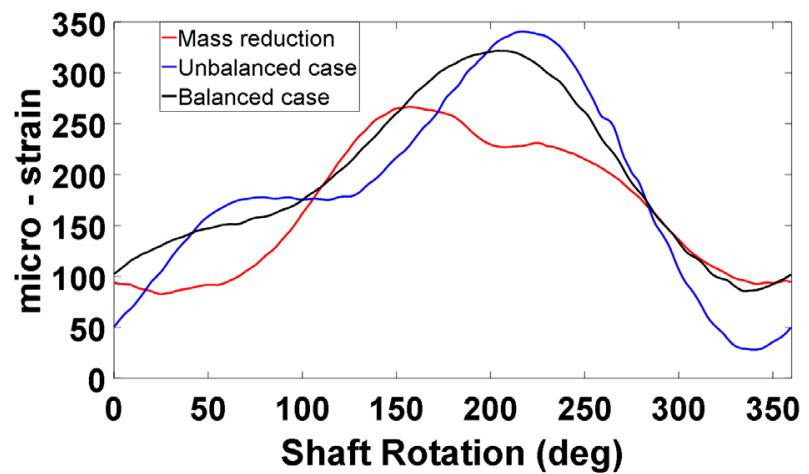

b)

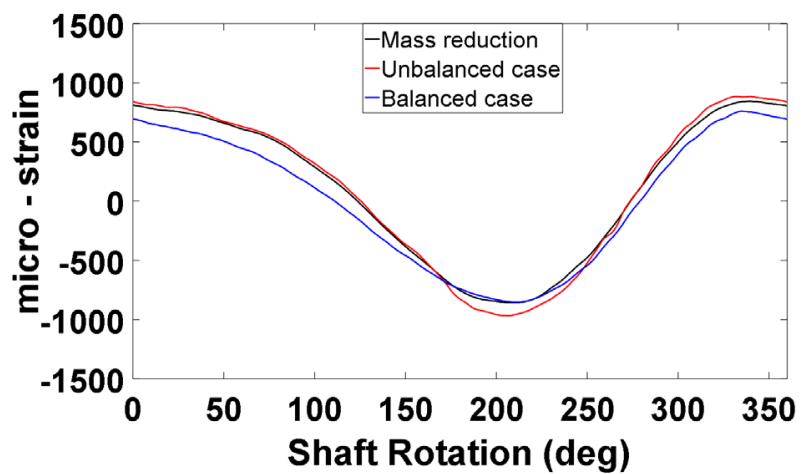

c)

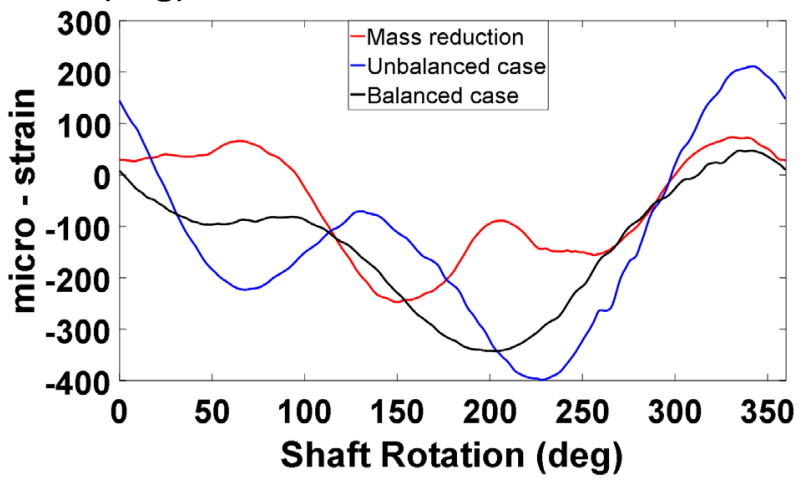

Figure 4. Blade strain measurements over exactly one revolution at $100 \mathrm{rpm}$ during mass reduction at the three modes; a) axial, b) in-plane, and c) out-of-plane. 


\subsection{Tower vibration response}

The imbalance effect due to the added $200 \mathrm{~g}$ mass caused an increase in the tower vibration fluctuation due to the coupling with the blade vibrational modes, and additional dynamic bending of the main drive shaft.

The tower vibration was further affected by the mass flying off as can be seen by the triaxial acceleration measurements shown in figure 5. The maximum acceleration was measured to be in the in-plane (Z) and out-of-plane $(Y)$ rotor directions at 49.65 seconds when the mass reduction event occurred.

a)

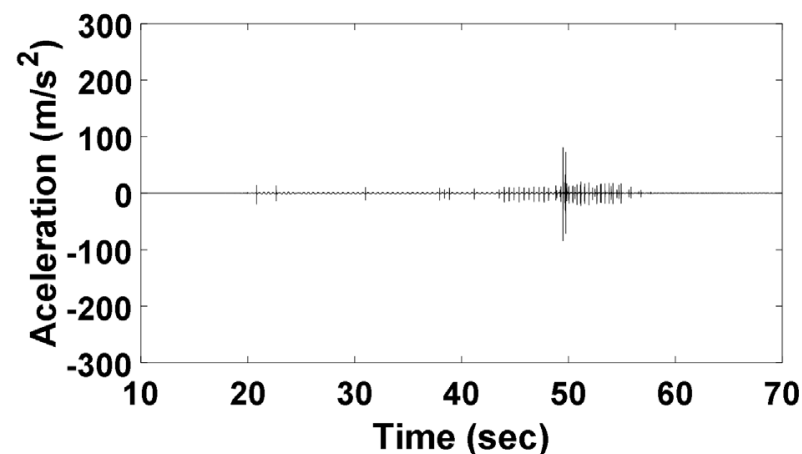

b)

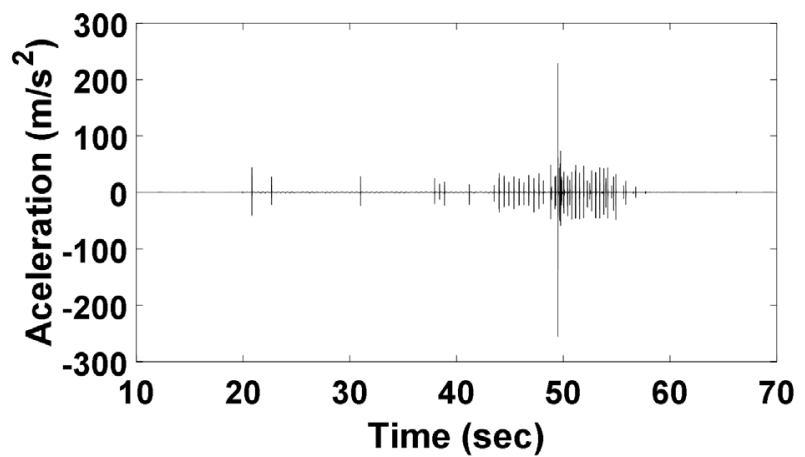

c)

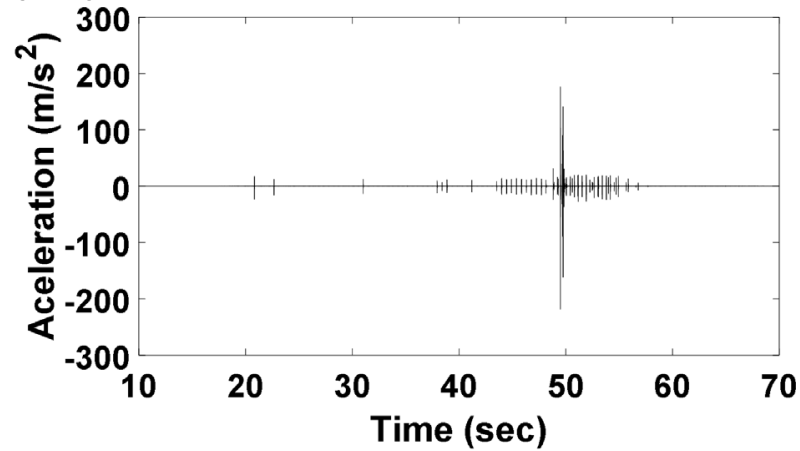

Figure 5. Tower acceleration-time domain at $100 \mathrm{rpm}$ during $200 \mathrm{~g}$ mass reduction by the tri-axial accelerometer, a) $\mathrm{X}$-axis, b) $\mathrm{Y}$-axis, and c) Z-axis.

Frequency analysis of the acceleration response subsequent to the mass removal showed that the lower order modes of the tower vibration were excited by the transient nature of the event. The significant out-of-plane response further confirms the coupling between the rotor behaviour and the tower response.

\subsection{Main rotor shaft displacement response}

The relative displacement response of the rotor shaft is monitored through laser sensors located orthogonally in axes 1 and 2. Figure 6 illustrates the orientation of axes 1 and 2 positioned perpendicular to the rotor shaft, as viewed from the drive end [14]. 


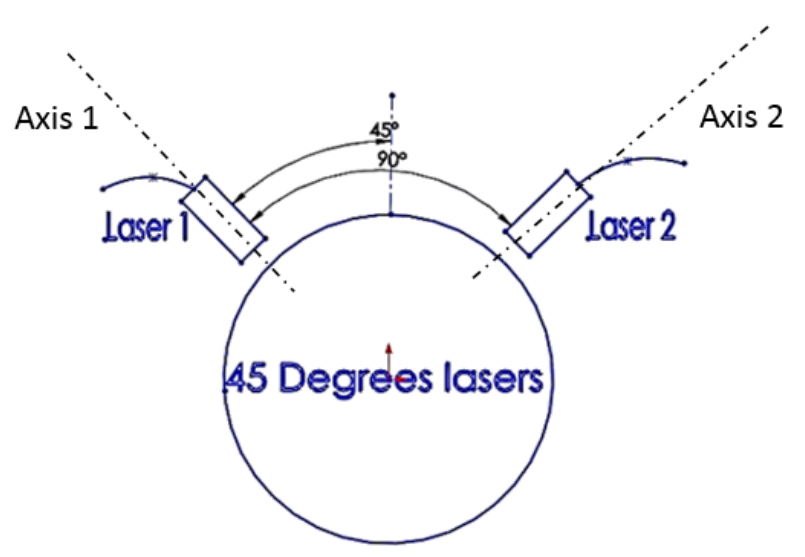

Figure 6. Configuration of orthogonal laser probes on the rotor shaft with axes 1 and 2, viewed from the shaft drive end.

Figure 7 shows the orthogonal laser shaft displacements during the $200 \mathrm{~g}$ mass reduction event where the transition from the unbalanced mass to the normal state, through the transient event can be seen. The nominal offset distance between the laser and the shaft surface of $24 \mathrm{~mm}$ should also be noted. Additionally, it can be noted that changes in shaft fluctuation occurred during the transition from unbalanced to the balanced condition, after the mass reduction event at $49.65 \mathrm{sec}$. It should also be noted that the shaft motion in the direction of axis 1 is significantly larger than the motion in the direction of axis 2 , most likely resulting from the differences in the stiffness and the forcing between the two directions.

a)

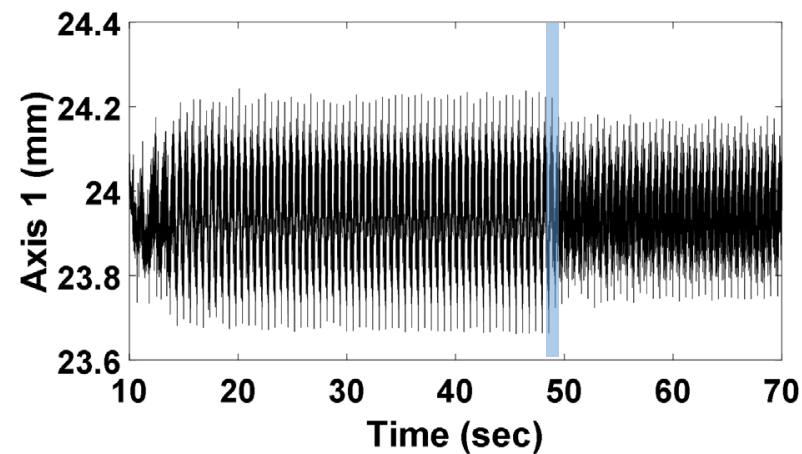

b)

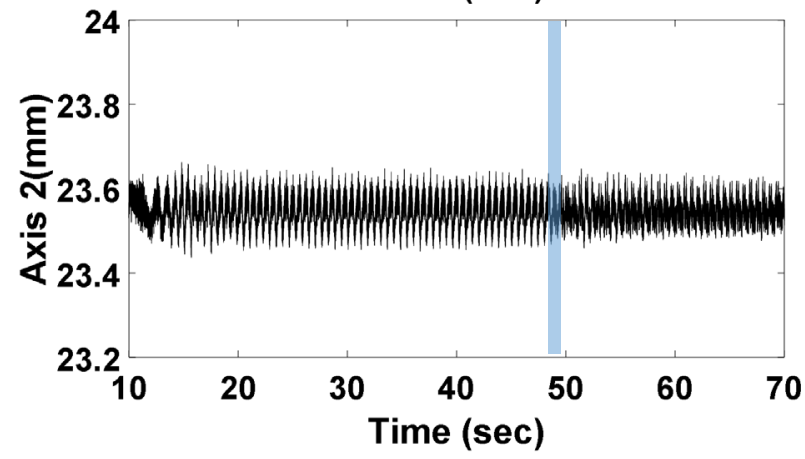

Figure 7. Effective Shaft displacements through laser measurements at $100 \mathrm{rpm}$ towards a) axis 1 , and $b$ ) axis 2 , showing the mass reduction event. 
The initial shaft displacement can be seen to be of the order of 500 microns in axis 1 and around 200 microns in axis 2 during the initial test period. The corresponding orbit plots where the shaft displacement in axis 1 and axis 2 directions are plotted simultaneously against each other are shown in Figure 8 . Figures $8 \mathrm{a}, \mathrm{b}$ and $\mathrm{c}$ indicate two seconds of shaft orbit motion that occurred just prior to the mass coming off, during the mass-came-off event and then after the event when the rotor returned to its balanced condition, respectively.

a)

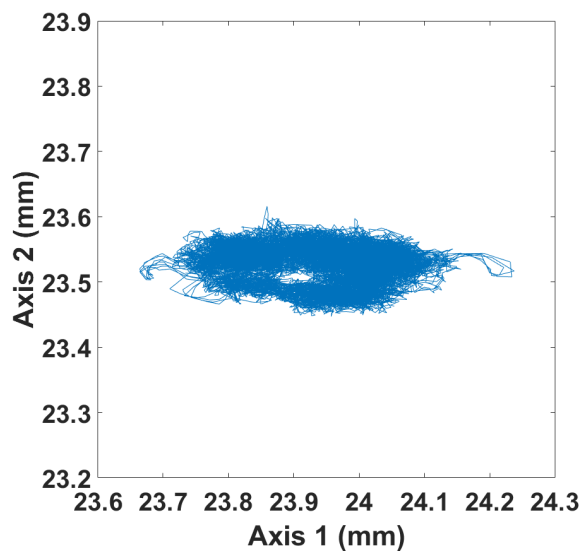

b)

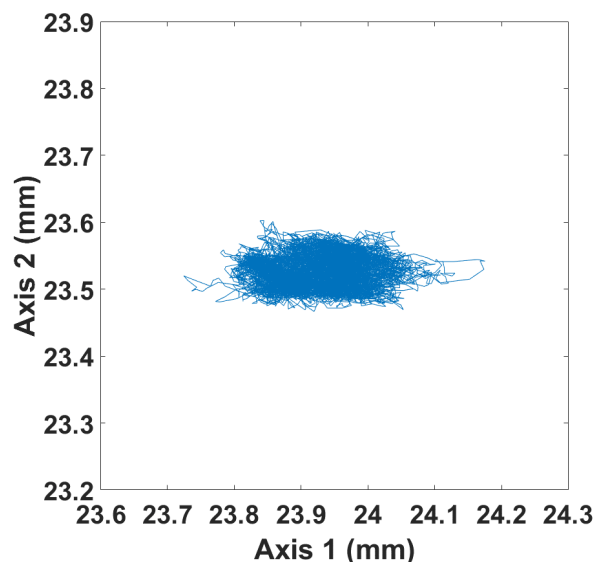

c)

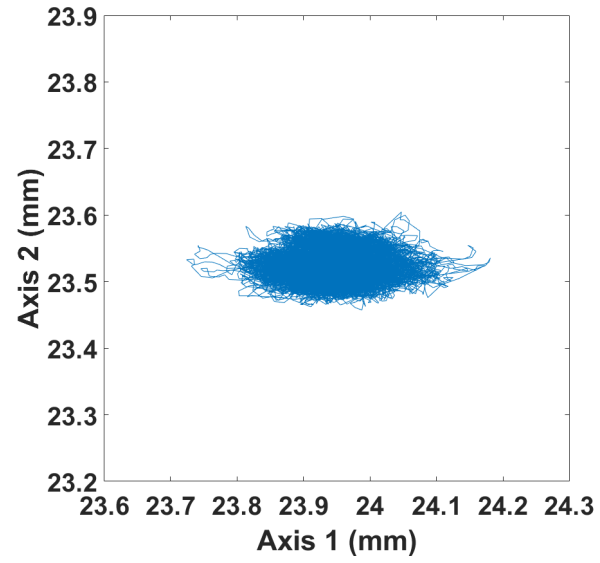

Figure 8. Two seconds of orbit motion of the drive shaft at $100 \mathrm{rpm}$, a) before the mass reduction, b) at the mass removal time, $c$ ) after the mass removal from the rotor blade.

Further shaft phase analysis of the orbit motion is shown in figure 9. This analysis utilises the encoder signal from the servo motor to calculate exact shaft revolutions of the orbit data. Each shaft rotation is then plotted separately on the vertical axis of the figure. The significance of this analysis is that each shaft rotation can be observed along the vertical axis of figure 9 , from the original imbalance condition with added $200 \mathrm{~g}$ mass, to the new balance state during the test. The initial start-up and ramp-down sections of the test can also be clearly observed.

The filtered shaft centreline orbits for every revolution of the rotor gives improved understanding of the instantaneous system behaviour and shows the possibility of identifying any revolution with significant changes. The mass removal can be detected between revolution 62 and 68, occurring exactly during revolution 66, whereby the amplitude of the 
revolutions transition from high amplitude to low amplitude as the system returns to the balanced situation.

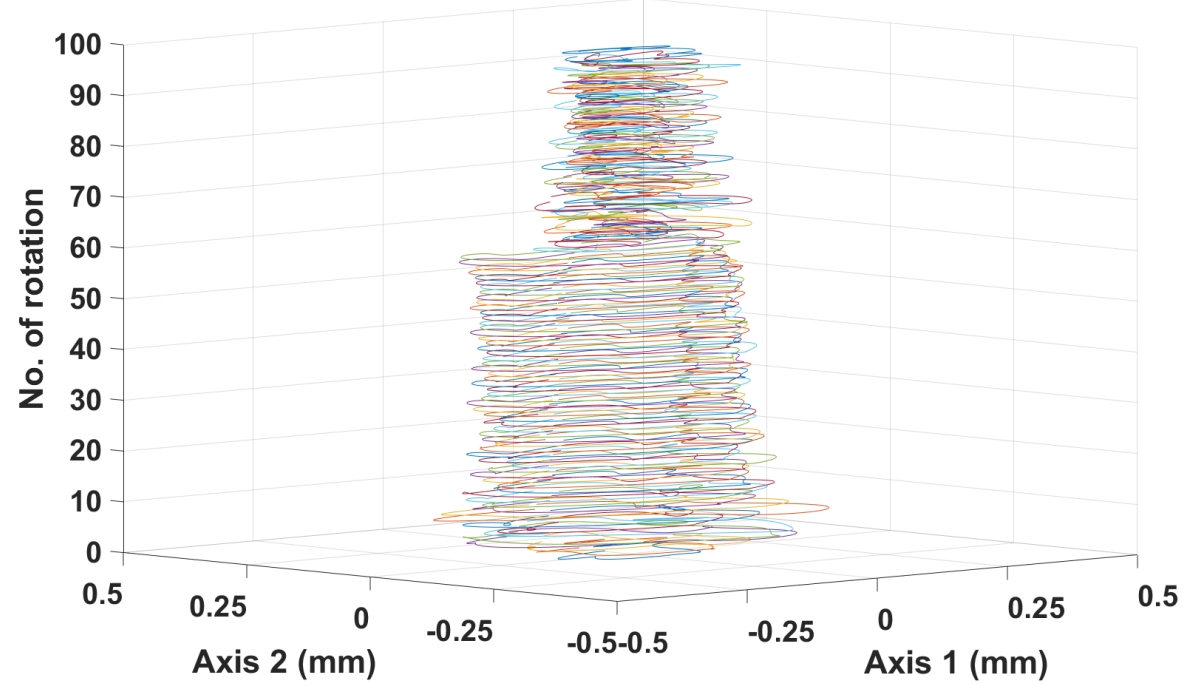

Figure 9. Calculated shaft orbits for every rotation at $100 \mathrm{rpm}$ during the $200 \mathrm{~g}$ mass reduction event measured by laser sensors at axes 1 and 2 .

Further, figure 10 illustrates the average drive shaft amplitude per one revolution at $100 \mathrm{rpm}$ corresponding to axes 1 and 2 for the two cases of imbalance with the mass removal event, compared with the balanced condition. This figure shows that the shaft amplitude towards axis 1 is higher than axis 2, where the maximum average shaft amplitude is 470 microns pkpk towards axis 1 with the added $200 \mathrm{~g}$ mass, whereas the maximum average shaft amplitude at axis 2 is 200 microns pk-pk at the same conditions. This difference between the deflection in the two axes directions can also be seen from the results shown in figures 8,9 and 10. Again the phase shift in the motion between the unbalanced and balanced case can be noted. 
a)
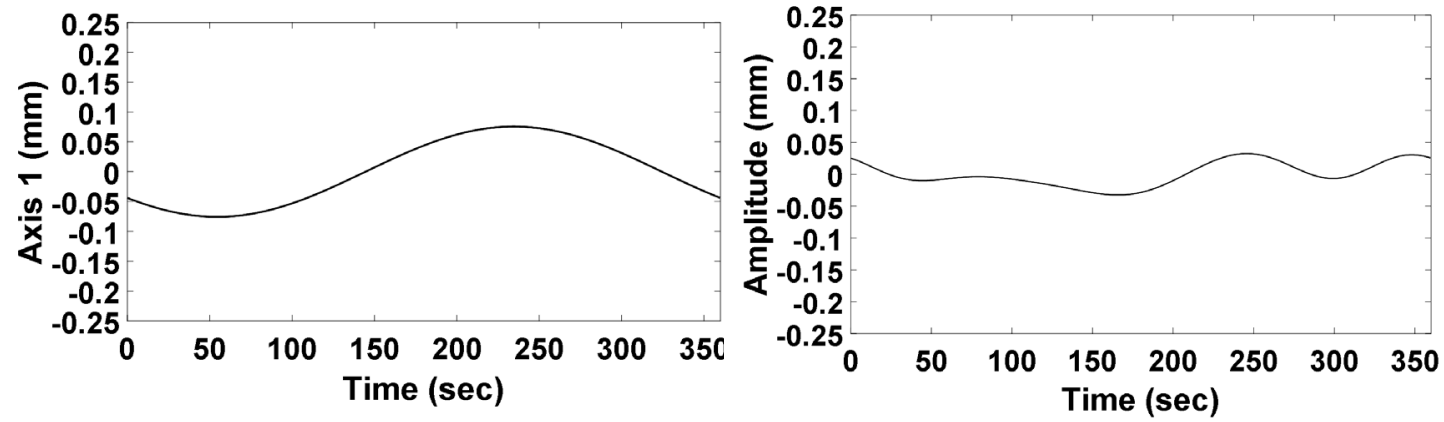

b)
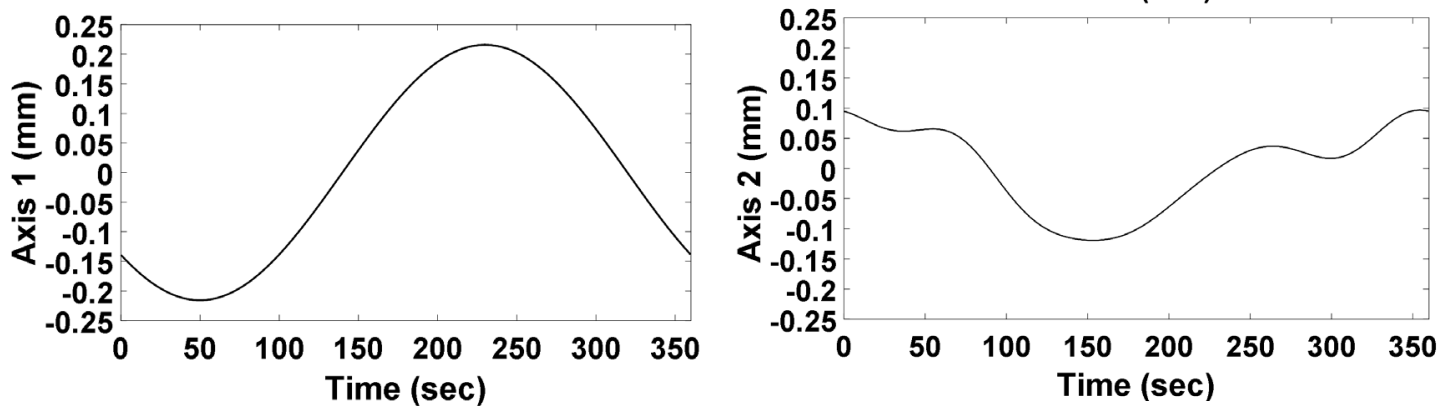

c)
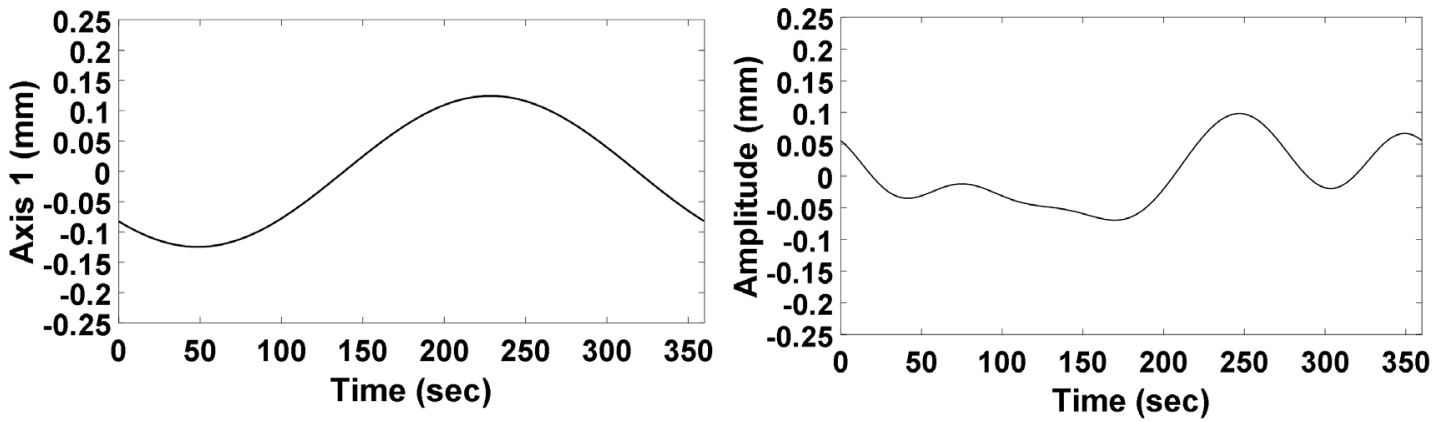

Figure 10. Horizontal and vertical shaft displacements per one rotation measured by laser sensors at a) mass reduction, b) unbalance case, and c) balanced (normal) rotation at $100 \mathrm{rpm}$.

Table 2 shows the average experimental peak-peak shaft amplitude of the various case studies, corresponding to the laser sensors on axes 1 and 2 . The unbalance results in a near doubling of the relative shaft motion when compared to the balanced shaft behaviour. The transient mass reduction event is somewhat less, seemingly caused by the transient behaviour of the system prior to the return to stable motion.

Table 2. Measured orthogonal shaft displacements for different conditions.

\begin{tabular}{ccc}
\hline Condition & $\begin{array}{c}\text { Axis 1 displacement } \\
\text { (pk-pk microns) }\end{array}$ & $\begin{array}{c}\text { Axis 2 displacement } \\
\text { (pk-pk microns) }\end{array}$ \\
\hline Mass reduction & 180 & 100 \\
Unbalance case & 470 & 180 \\
Balanced case & 230 & 110 \\
\hline
\end{tabular}

Complex frequency domain filtering is another helpful method for monitoring the drive shaft centre line displacements, where the resulting orbit configuration indicates the averaged 
shaft centre line path for various shaft rotation order components as shown in figure 11. Subsequent FFT analysis results in shaft order +ve and -ve frequencies of the periodic shaft order analysis that provides for simple shaft order filtering and display [15]. The resulting shaft rotation order components can be combined to obtain the complex periodic displacement signal.

The unbalanced and balanced cases shown in figure 11 illustrate the difference between the shaft fluctuations. These results show the shift in shaft centre line's displacement during the change from the unbalanced to balanced case, passing through the transient case (mass reduction). Furthermore, it illustrates the change in the centre line path when shaft harmonics $2 x, 3 x$ and $4 x$ are included. In particular it helps to show the rapid change from the unbalanced case when the mass reduction occurs, showing that the orbit motion changes within one revolution of the rotor, though it takes several rotations for the mass reduction transient effect to dampen out and for the system to return to the balanced condition, as also observed in Figure 9.

(a)

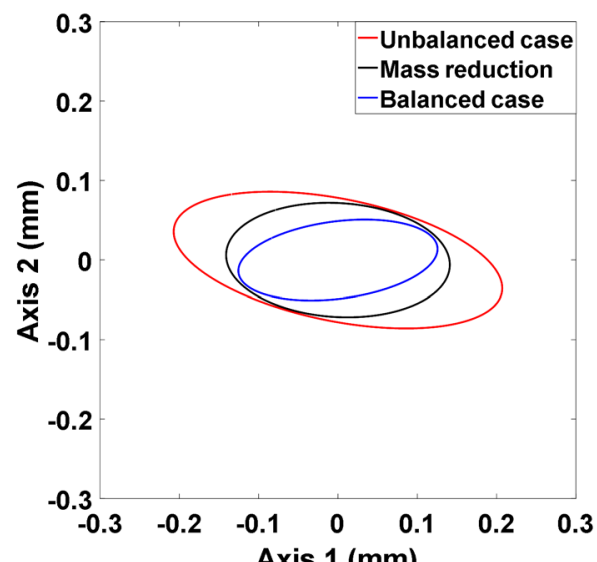

(c)

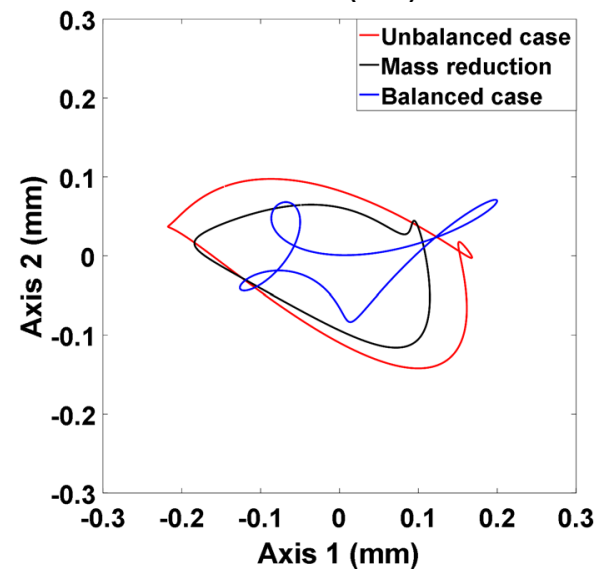

(b)

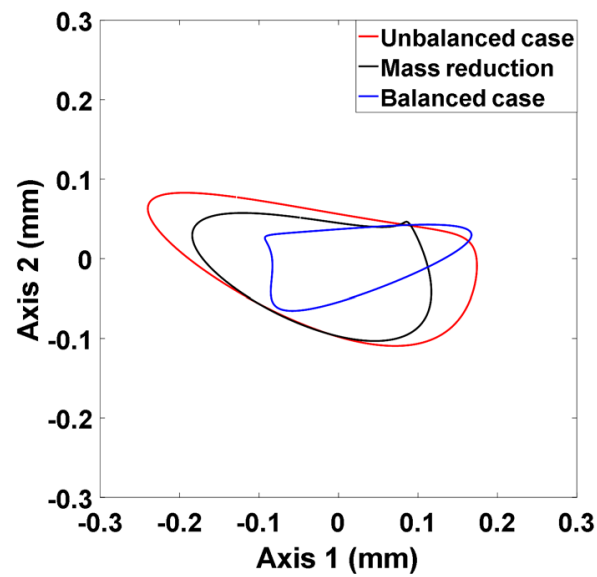

(d)

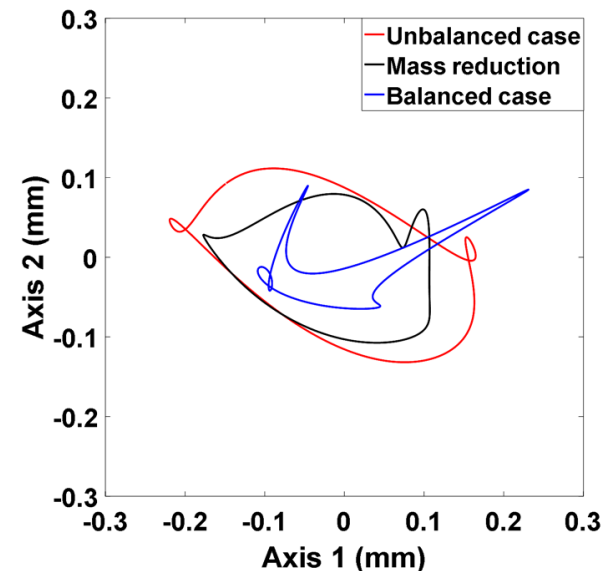

Figure 11. Filtered shaft orbit plots at $100 \mathrm{rpm}$ for the unbalanced and balanced cases in comparison to the mass reduction event a) $1 X$, b) $2 X$, c) $3 X$, and d) $4 X$.

The excitation of transient high frequency components during the mass came-off event at 49.65 seconds $(0.8275 \mathrm{~min}$ ) can be identified by time-frequency spectrogram analysis from 
the axial, in-plane, and out-of-plane dynamic strain data obtained from blade 1, as shown in Figure 12.

The spectrogram analysis clearly shows the rotational speed of the rotor at $100 \mathrm{rpm}(1.67 \mathrm{~Hz})$ and higher harmonics. The analysis also shows that significant changes occurred to the strain waveforms during the transient event, especially between 2 and $5 \mathrm{~Hz}$, which is pronounced in all blade modes in figure $12,[16]$.

a)

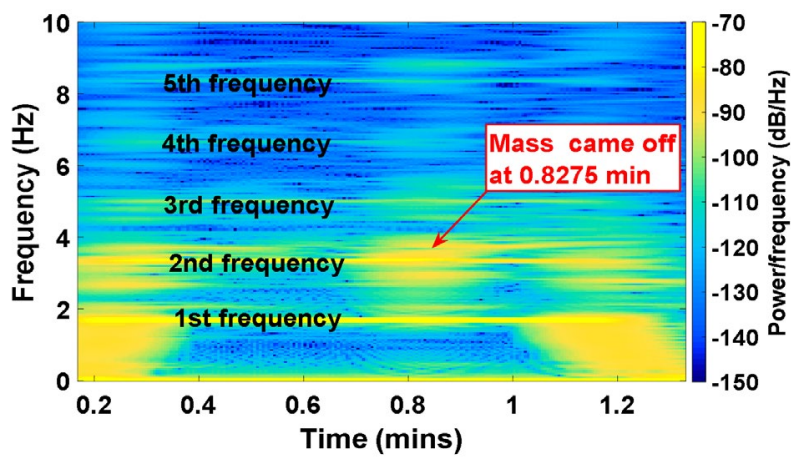

b)

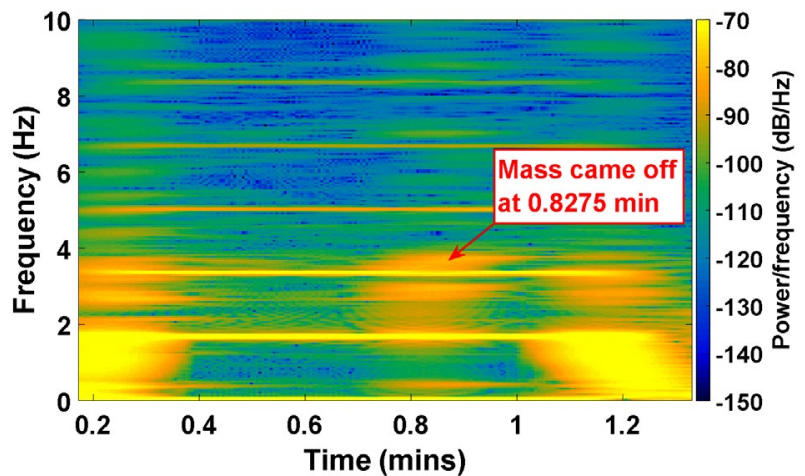

c)

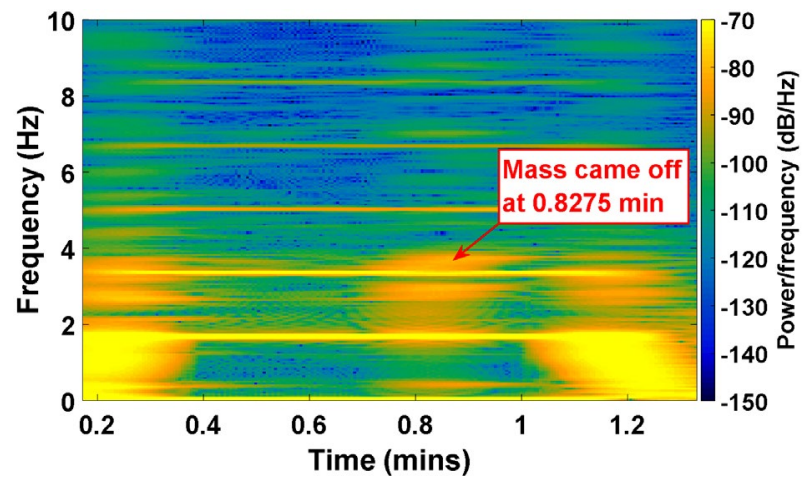

Figure 12. Spectrogram analysis of the rotor blade strain data a) axial, b) in-plane, and c) out-ofplane, at $100 \mathrm{rpm}$ during the mass reduction event.

Further, the transient mass reduction event affected the support tower vibrations, as seen through the spectrogram analysis shown in figure 13. This analysis used the measurements from the high sensitivity triaxial accelerometer, positioned on the upper part of the tower which measured dynamic vibrations based on the orthogonal $X-Y-Z$ directions. These results show that the tower vibration during the transient mass removal was excited in all directions simultaneously at $0.8275 \mathrm{~min}$. According to the spectrogram analysis, significant coupling of the vibration occurred in the $X, Y$ and $Z$ directions during this transient event. In particular, the transient mass reduction event that occurred from blade 1, rotating at $100 \mathrm{rpm}$, can be seen to excite a wide frequency response to the tower, for all directions. The fundamental tower resonance around $2 \mathrm{~Hz}$ is clearly visible [16], though the rotor speed and harmonics are more difficult to observe. 
a)

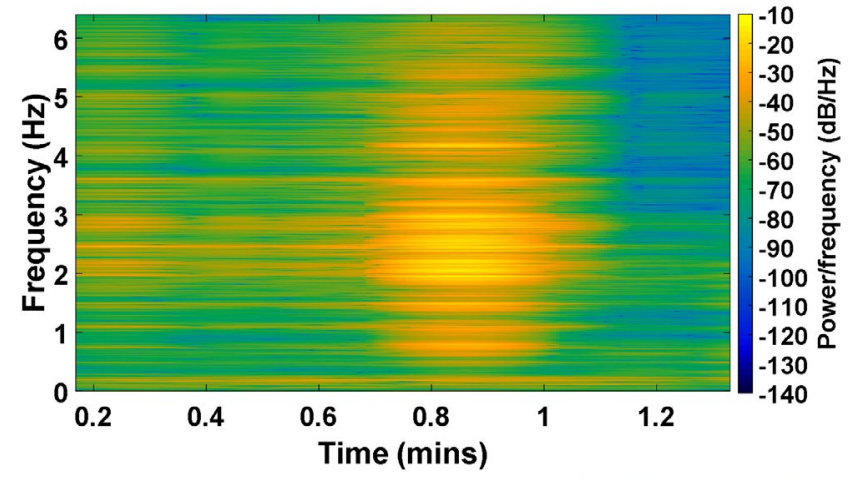

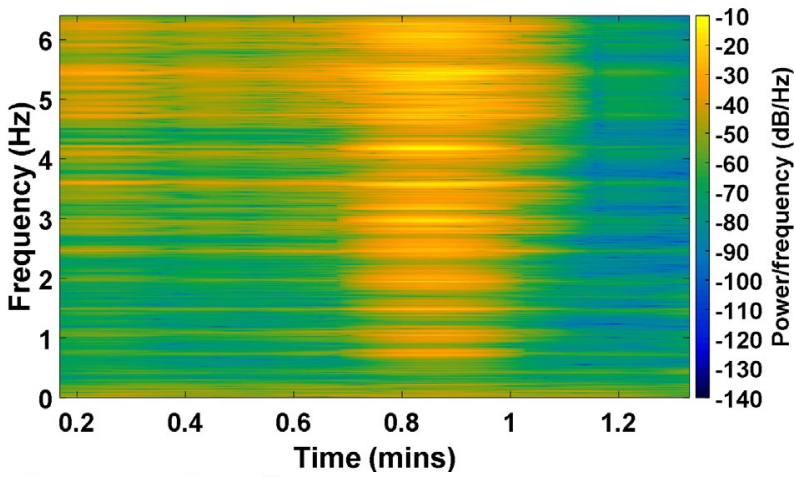

c)

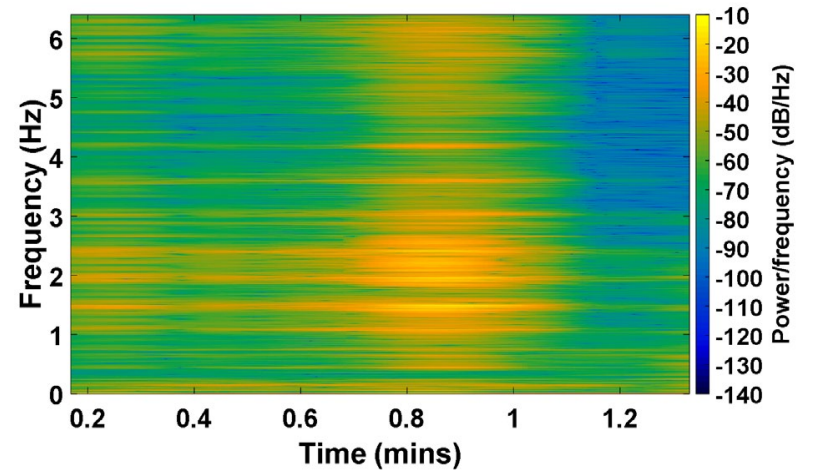

Figure 13. Spectrogram analysis of the tower vibrations during the mass removal event a) $X$-axis, b) $\mathrm{Y}$-axis, and c) Z-axis, from the triaxial accelerometer.

\section{Transient mass collision on to the rotor blade}

Large horizontal axis wind turbines are known to experience mass collision events on to their rotating blades during operation, which can subsequently induce fatigue damage and ensuing blade failure in some cases. Most of the mass strikes are migratory birds or eagles that have a negative effect on the glass fiber reinforced materials of which the blades were made from. The mass collision event for these tests was modelled by a $200 \mathrm{~g}$ fabric and leather mass, thrown horizontally upon the face of the rotating blade in the $\mathrm{Y}$ out-of-plane direction, while the rotor was operating at $100 \mathrm{rpm}$. The velocity of the impact was of the order of $1 \mathrm{~m} / \mathrm{s}$.

Figure 14 illustrates the measured blade strains during a mass collision event onto blade 1. The impact event can be seen in each of the strain results, while the out-of-plane and in-plane responses are higher than the axial strains due to the high dynamic bending of the blade that resulted from the mass collision. 

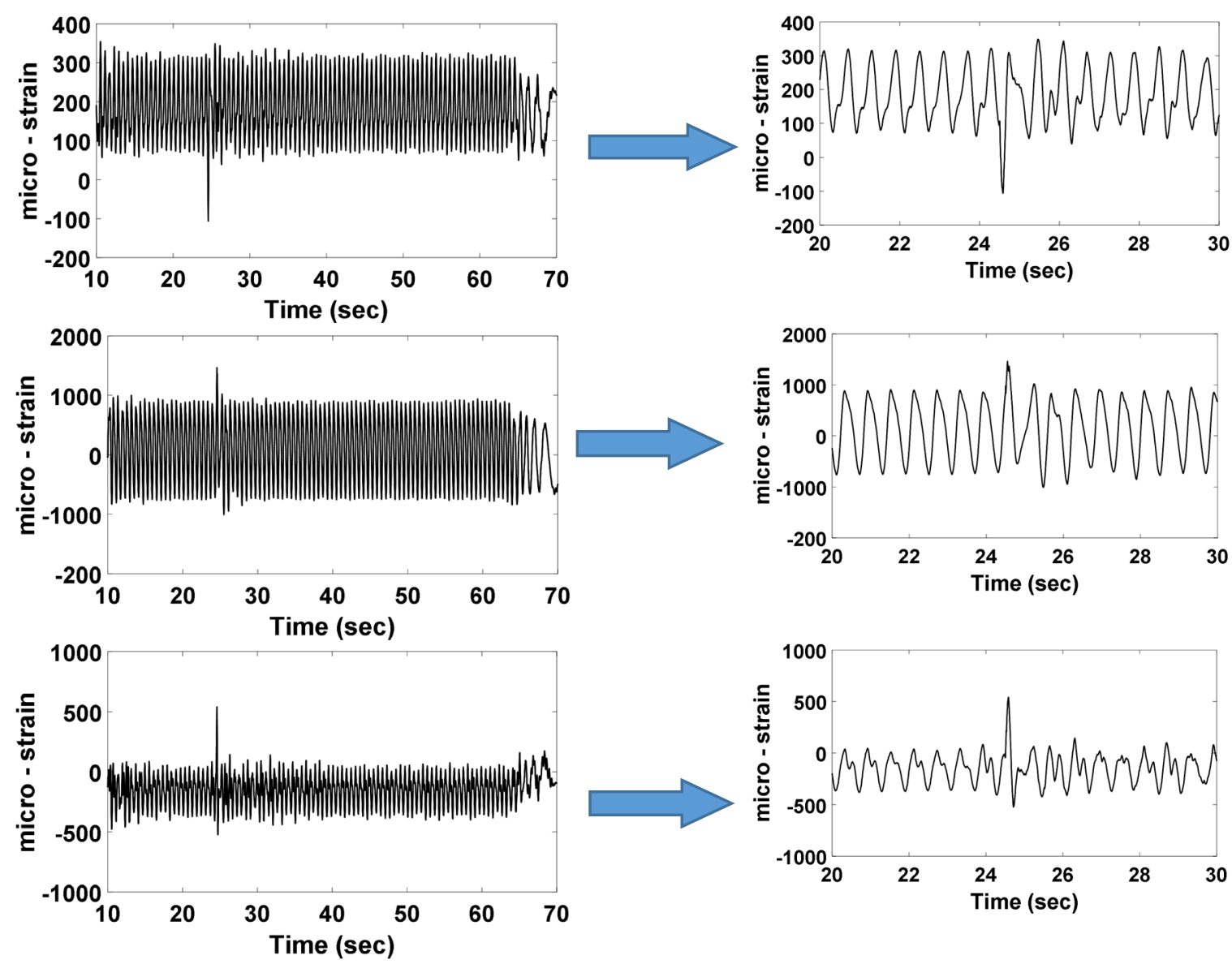

Figure 14. Transient blade strain from mass collision at time 24.60 seconds to the blade rotating at $100 \mathrm{rpm}, \mathrm{a})$ axial, b) in-plane and c) out-of-plane.

Figure 15 illustrates the once per rotation blade strain behaviour during the mass collision with the rotor blade, including the transition stage between the balanced and unbalanced cases. Different behaviour can be identified corresponding to the fault condition. Increase in blade strain vibrations have been identified after the collision with the rotor blade, where maximum blade axial strain occurs at the unbalanced case (340.8 $\mu$ strain), while maximum blade in-plane strain is $966.8 \mu$ strain (at the compression side) and maximum blade out-ofplane strain is $400 \mu$ strain (at the compression side). 
a)

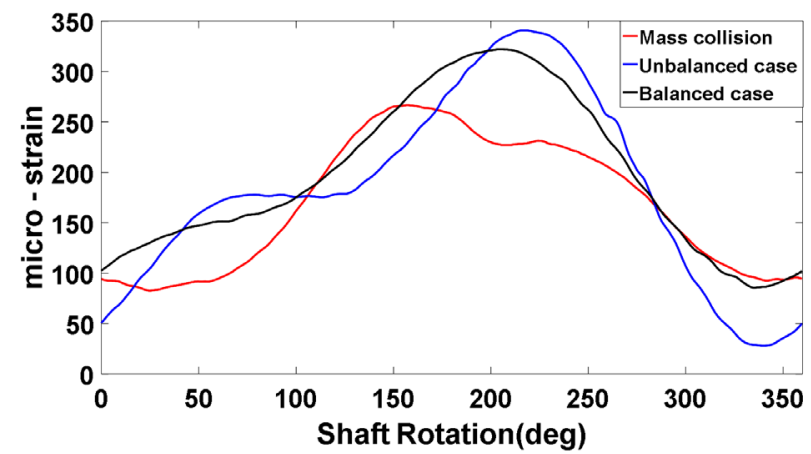

b)

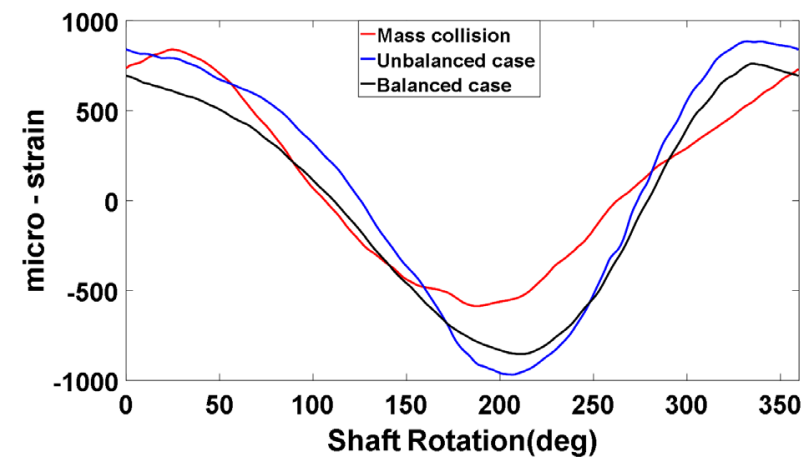

c)

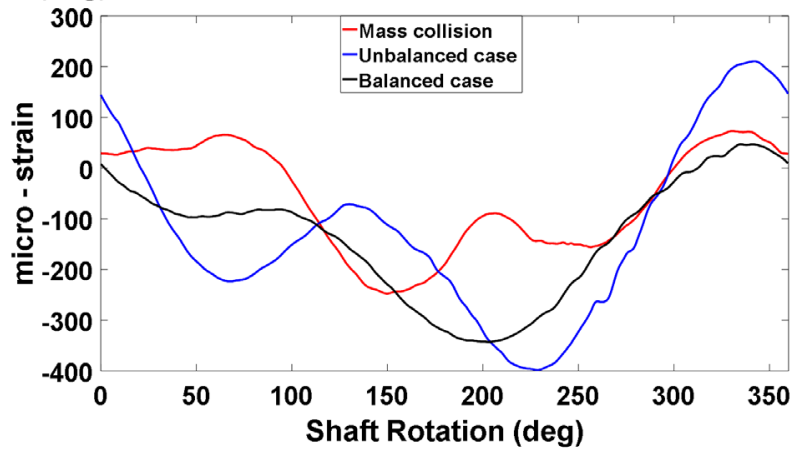

Figure 15. Blade strain based on measurements over exactly one revolution for balanced and unbalanced cases and comparison with the transient mass collision event at 24.60 seconds of a) axial strain amplitude, b) in-plane strain amplitude, and c) out-of-plane strain amplitude.

The collision effect was also transferred to the tower vibration and was identified by monitoring the tower vibration amplitude using the triaxial accelerometer. Figure 16 shows the acceleration amplitude in the $X, Y$, and $Z$ directions during the collision time. The maximum acceleration amplitude was in the $Z$-direction and occurred due to the high in-plane vibration resulting from the collision. Additionally, the Y-direction vibration further increased showing an increase in the out-of-plane vibrations. Only a small increase in the tower vibration in the X-direction was seen, compared to the other directions.

The tower acceleration response for the mass collision event can be contrasted with the tower response shown in Figure 5, resulting from the transient mass reduction event. It should be see that the tower response is dramatically different in the two cases as the amplitude of the impulsive kinetic energy from the two events differs by a factor of approximately 100 . 
a)

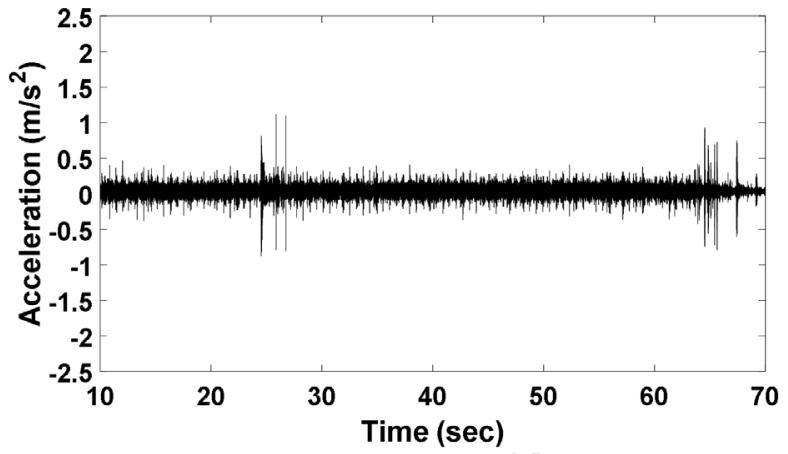

b)

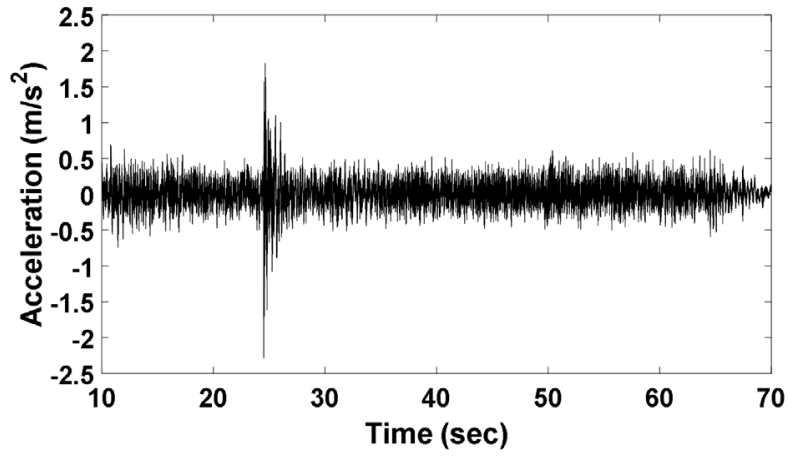

c)

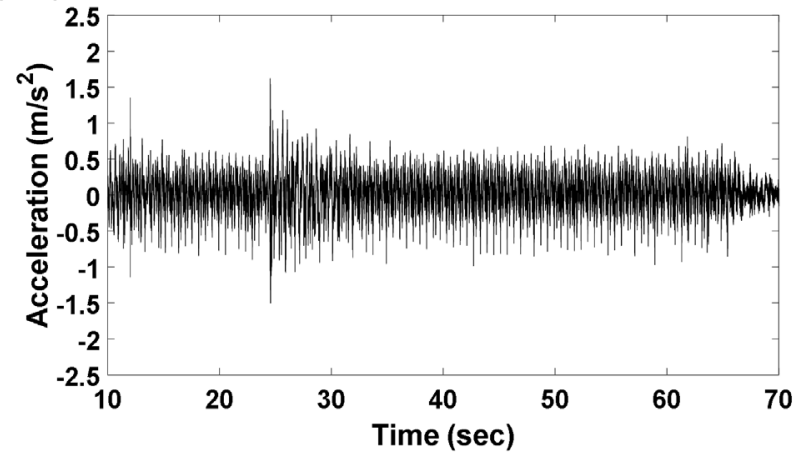

Figure 16. Tower vibration measured by the triaxial accelerometer during the mass collision event a) $\mathrm{X}$-direction, b) Y-direction, and c) Z-direction.

The collision was also observed to affect the relative shaft amplitude motion as shown in figure 17, where the transient impact onto blade 1 led to fluctuations in the drive shaft motion, which has been detected by the lasers sensors. Even though the shaft motion of axis 1 is larger than axis 2 , the collision event was still noticeable in both directions.

a)

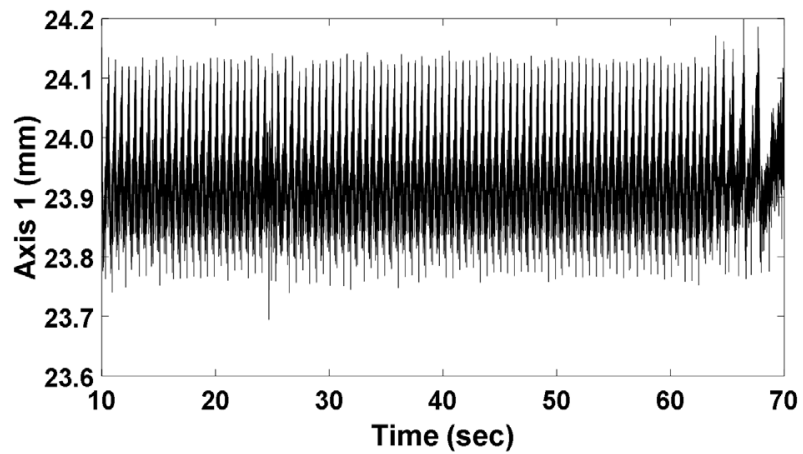

b)

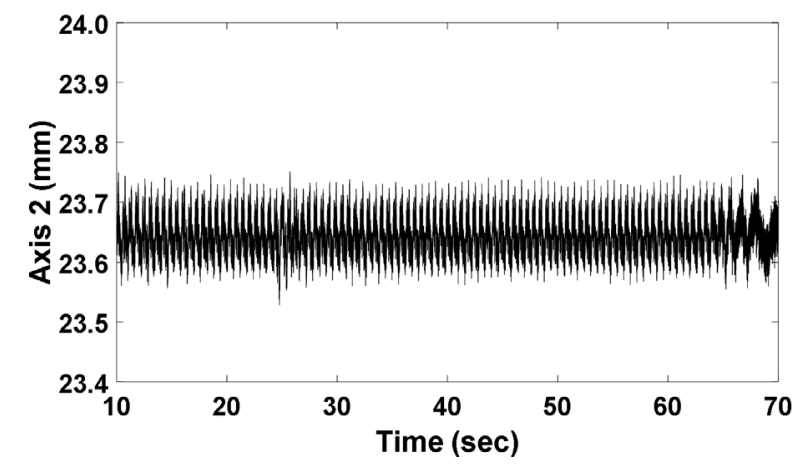

Figure 17. Shaft displacements at $100 \mathrm{rpm}$ measured by the lasers during a mass collision at 24.60 seconds, a) axis 1 , and b) axis 2 .

Further, figure 18a illustrates the shaft centre line orbit of a two second period before the collision event ( 24.60 seconds), figure $18 \mathrm{~b}$ shows the shaft centre line motion during the mass collision, while figure $18 \mathrm{c}$ shows the shaft motion after the collision event. The differences between the orbits can be attributed to the pronounced effect of the collision event on the shaft dynamic displacement. The transient behaviour of the shaft motion during the collision 
event is easily discernible. The motion afterward is also different from prior to the event as the dynamic effects take some time before they dampen out. This can also be seen in the raw measurements shown in Figure 17.

a)

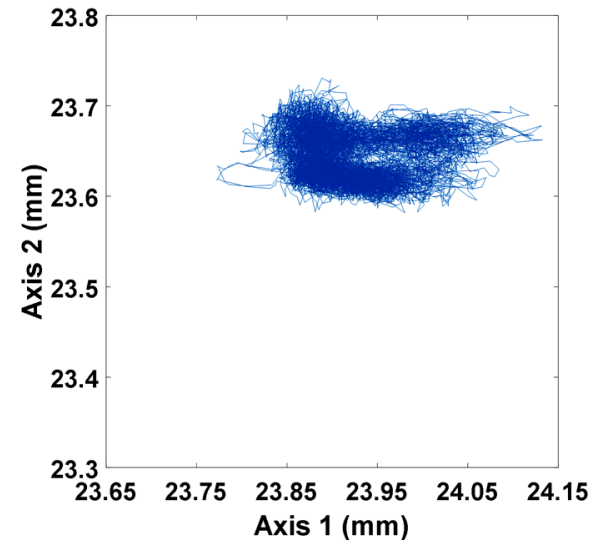

b)

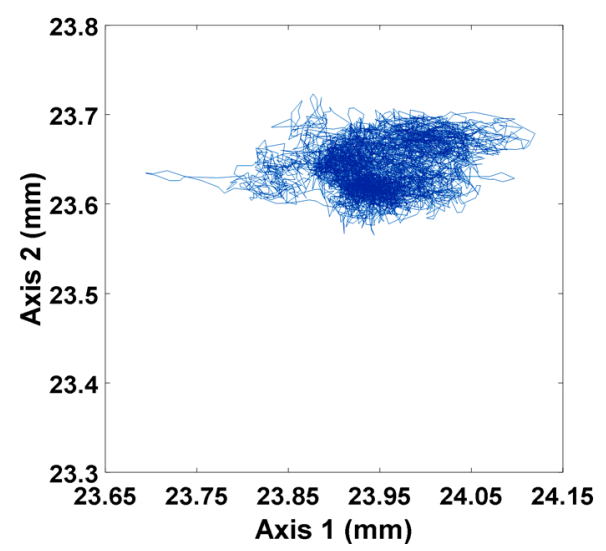

c)

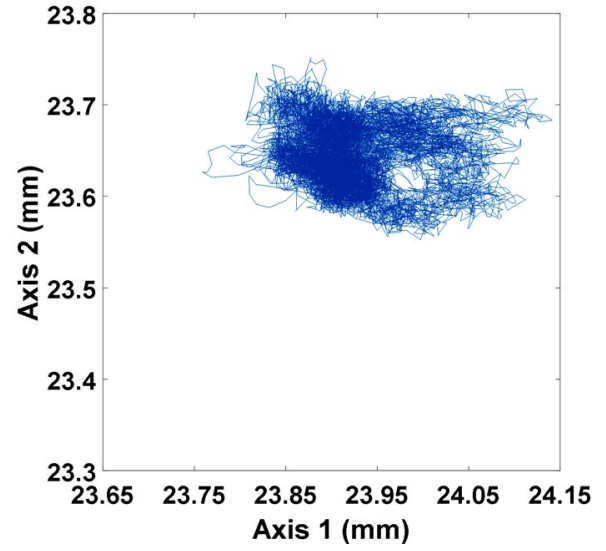

Figure 18. Orbit analysis of the shaft displacement at axes 1 and 2 directions measured by lasers at $100 \mathrm{rpm}$ a) before mass collision and b) during the collision time, and c) after the collision.

Figure 19 represents the shaft orbit and tower accelerations for each revolution during the collision test. Figure 19a shows the shaft orbits per each revolution measured by laser sensors, indicating the transient mass collision occurred during revolution 29 at $24.60 \mathrm{sec}$, whereas figure $19 \mathrm{~b}$ shows the in-plane and out-of-plane acceleration results ( $Z$ and $Y$ axes) from the triaxial accelerometer to show the collision response. 
a)

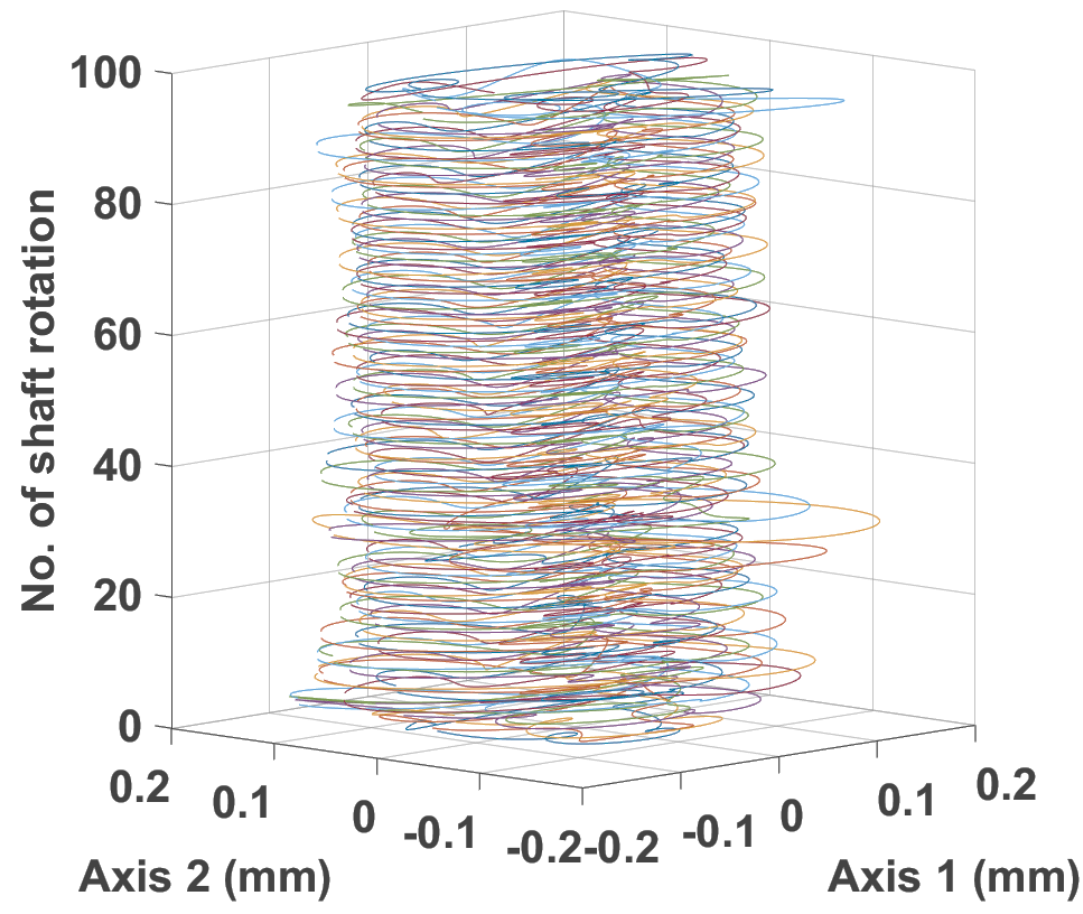

b)

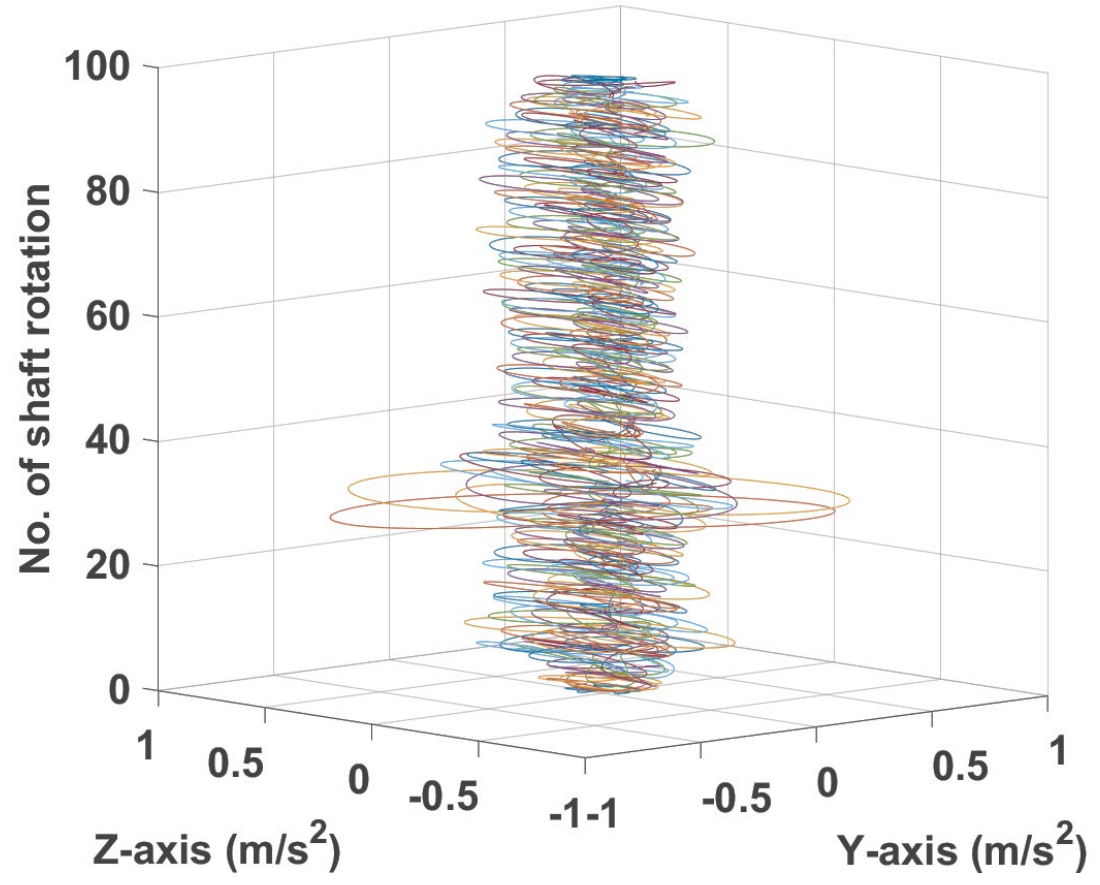

Figure 19. Calculated shaft and tower orbit responses for every rotation at $100 \mathrm{rpm}$ during the $200 \mathrm{~g}$ mass collision test a) laser signal data, b) triaxial accelerometer signal data.

Figure 20 illustrates the comparison of the relative shaft centre line orbits for both transient events measured by the lasers, including the effects of the first four shaft harmonics. Different behaviour can be identified between the incidents. These differences will be affected by the nature of the mass reduction and collision events, especially in the orientation of the collision. 
(a)

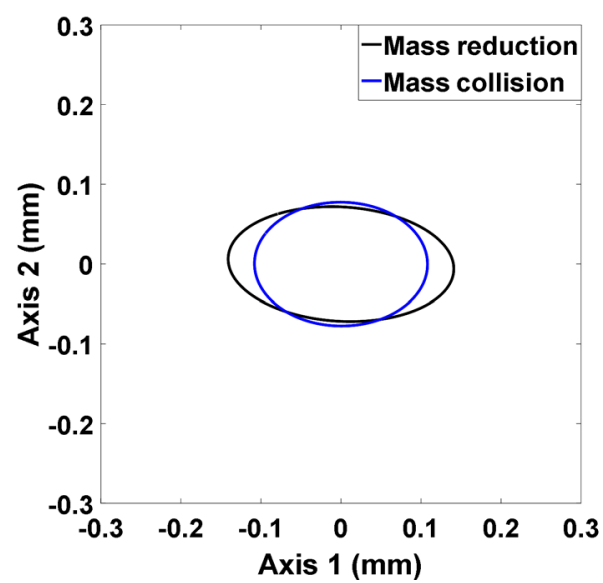

(c)

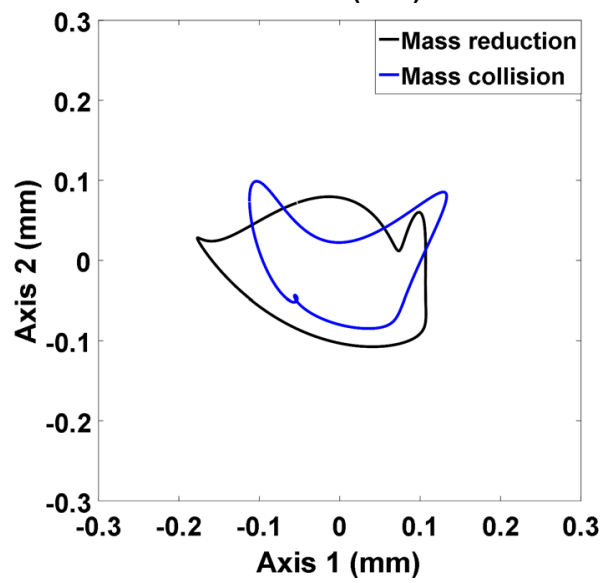

(b)

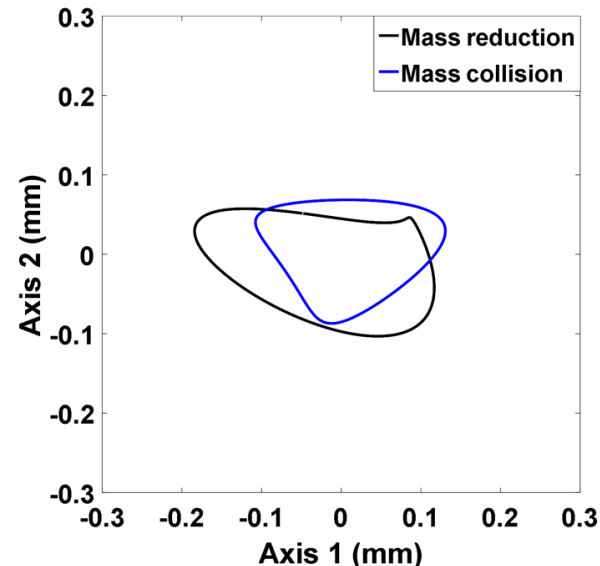

(d)

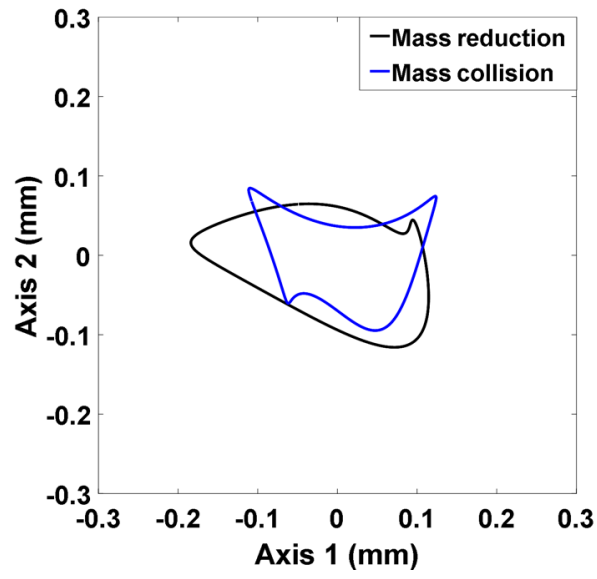

Figure 20. Filtered shaft orbit plots at $100 \mathrm{rpm}$ for the mass reduction and mass collision fault conditions including shaft harmonics a) $1 X$, b) $2 X$, c) $3 X$, and d) $4 X$.

\section{Conclusions}

This paper presents the detail and analysis of experimental case studies with blade faults on a small scale horizontal axis wind turbine test rig. The test rig was designed for implementing different artificial faults and for providing measurements using rotating and non-rotating sensors operating at various speeds. The range of sensors included blade strain in axial, inplane and out-of-plane directions, blade acceleration, shaft relative displacement in two orthogonal directions, and tower triaxial vibration measurements. Shaft rotation was also measured to facilitate synchronous signal averaging and subsequent shaft phase analysis.

A novel incident occurred at $100 \mathrm{rpm}$ where an attached $200 \mathrm{~g}$ mass came off from the rotating blade during a test. A further test was conducted where a $200 \mathrm{~g}$ mass was made to collide with the same blade, again at the same shaft speed. These case studies were also compared with balanced operation. The case studies have shown the following conclusions that can inform larger scale wind turbine fault detection and diagnosis.

Blade root strain measurements have been shown to be effective for quantifying the blade loading and its variation in the axial, in-plane and out-of-plane component directions during shaft rotation. Any changes to the blade mass have been shown to directly affect these strains, with very rapid indications being measured. Synchronous signal averaging of these 
strain components as a function of shaft phase has shown significant sensitivity to changes in mass, especially for the axial and out-of-plane directions. The out-of-plane strain is influenced by coupling with gravity loading affects, which in turn is influenced by the mass loading.

Rapid mass reduction at speed affects the tower vibration, most particularly in the rotor inplane and out-of-plane axes, confirming the coupling between the rotor behaviour and the tower response.

Measurement of the relative orthogonal shaft deflection and shaft phase provides effective means of monitoring dynamic imbalance conditions of the rotor. Subsequent shaft orbit motion can be used to determine the shaft dynamic response during each revolution of the rotor and has been shown to be effective at detecting rapid mass-loss and mass-collision events. Mass removal and mass-collision events directly affect the main shaft motion. The monitoring of each of the specific orbit shaft order frequency components is a powerful method for detecting any transient events affecting the rotor system and these case studies have confirmed the coupling between the rotor behaviour and the main shaft deflection.

Spectrogram time-frequency analysis has confirmed the ability to detect transient mass events in the raw blade root strain components and the tower accelerations. This provides further evidence of the coupling between the tower and rotor for mass loading events.

The kinetic energy involved in the mass-reduction event was of the order of 100 times larger than the mass-collision event in these case studies. The out-of-plane mass collision event onto the rotor blade was shown to be detectable on all the blade strain components, with the largest change occurring in the out-of-plane strain as expected. The tower acceleration and main shaft deflection were significantly affected by the mass collision event, providing further evidence of the significant coupling between the rotor, main shaft and tower vibration components.

The case studies have confirmed the sensitivity of rotating and non-rotating sensors for detecting and quantifying transient mass loading events and show opportunities for further development for improving condition monitoring methods for wind turbine fault detection.

\section{Acknowledgements}

This work was supported by the Iraqi Ministry of Higher Education.

\section{References}

1. Hu, C., R. Albertani, and R.M. Suryan, Wind turbine sensor array for monitoring avian and bat collisions. Wind Energy, 2018. 21(4): p. 255-263.

2. Flowers, J., Albertani R, Hrrison T, Polagye B, Suryan RM., Design and initial component tests of an integrated avian and bat collision detection system for offshore wind turbines. 2014. 
3. Chen, X. and J.Z. Xu, Structural failure analysis of wind turbines impacted by super typhoon Usagi. Engineering Failure Analysis, 2016. 60: p. 391-404.

4. Chou, J.S. and Tu, W.T., Failure analysis and risk management of a collapsed large wind turbine tower. Engineering Failure Analysis, 2011. 18(1): p. 295-313.

5. Chou, J.-S., Chiu,C.,Huang,I., and Chi,K., Failure analysis of wind turbine blade under critical wind loads. Engineering Failure Analysis, 2013. 27: p. 99-118.

6. Chen, H.C., A study of wind turbine blade using advanced composite materials. Department of Aeronautics and Astronautics Engineering, National Cheng Kung University;Tainan (Taiwan):, 2007.

7. Chou,J.,Chiu,C.,Huang,I., and Chi,K., Failure analysis of wind turbine blade under critical wind loads. Department of construction engineering, National Taiwan University of Science and Technology, Engineering Failure Analysis, 2013. 27: p. 99-118.

8. Zhang, Z., Yin, Z., Han, T., and Tan, A.C., Fracture analysis of wind turbine main shaft. Engineering Failure Analysis, 2013. 34: p. 129-139.

9. Wang, K., D. Guo, and P.S. Heyns, The application of order tracking for vibration analysis of a varying speed rotor with a propagating transverse crack. Engineering Failure Analysis, 2012. 21: p. 91-101.

10. Chen, X., Zhao, W., Zhao, X.L., and Xu, J.Z., Preliminary failure investigation of a $52.3 \mathrm{~m}$ glass/epoxy composite wind turbine blade. Engineering Failure Analysis, 2014. 44: p. 345350.

11. Shen, G., Xiang, D., Zhu, K., Jiang, L., Shen, Y., and Li, Y., Fatigue failure mechanism of planetary gear train for wind turbine gearbox. Engineering Failure Analysis, 2018. 87: p. 96110.

12. Crabtree, C., Y. Feng, and P. Tavner. Detecting incipient wind turbine gearbox failure: a signal analysis method for on-line condition monitoring. in Proceedings of European Wind Energy Conference (EWEC 2010), Warsaw, Poland. 2010.

13. Baker, K., B. Douglas, and I. Howard. A review of orbit analysis for turbogenerator condition monitoring. in Proceedings of the First Australasian Congress on Applied Mechanics: ACAM96. 1996. Institution of Engineers, Australia.

14. Al-Hadad, M., Hwais, A., McKee, K., and Howard, I., Rotating and non-rotating sensors for improving condition monitoring of wind turbines. in 9th Australasian Congress on Applied Mechanics (ACAM9). 2017. Engineers Australia.

15. Howard, I., Omerovic, A and Morgan, L, Frequency Analysis for turbomachinary diagnostics. Fifth international congress on sound and vibration, 1997: p. 1001-1009.

16. Al-Hadad, M.A.S., McKee, K., and Howard, I., Vibration fault detection of fracture in a wind turbine tower foundation. Advances in Mechanics:Failure, Deformation, Fatigue, Waves and Monitoring, 2018. 